\title{
0 metaprojeto contra o controle por restrição na arquitetura
}

\author{
> Mateus de Sousa van Stralen \\ Universidade Federal de Minas Gerais, Brasil \\ mateus.stralen@gmail.com
}

> Ana Paula Baltazar dos Santos

Universidade Federal de Minas Gerais, Brasil

baltazar.ana@gmail.com

\author{
> José dos Santos Cabral Filho \\ Universidade Federal de Minas Gerais, Brasil \\ cabralfilho@gmail.com
}

\begin{abstract}
Este artigo discute o potencial de novas interfaces paramétricas que permitem ao usuário a manipulaçấo de parâmetros de projeto em tempo real. Inicialmente será abordada a relação entre processos de desenho paramétrico e fabricação digital. Em seguida será apresentado o processo de projeto de uma luminária paramétrica comparado a duas interfaces existentes - Mattermachine e Sketchchair. Como conclusão, é proposto que o processo de abertura de parâmetros adotados nas interfaces descritas seja uma possível alternativa ao crescente controle do processo de desenho e construção exercido por arquitetos, possibilitado pela associação entre as tecnologias digitais de desenho e de fabricação digital.
\end{abstract}

Keywords: Arquitetura Paramétrica; Desenho Aberto; Metaprojeto

\section{Introdução}

O presente artigo discute o potencial de novas interfaces paramétricas que permitem ao usuário a manipulação de parâmetros de projeto em tempo real, enfocando a produçáo de espaços arquitetônicos. Este potencial de manipulaçấo de parâmetros pelo usuário permanece pouco explorado na arquitetura. Nas últimas décadas o computador mudou de forma radical alguns aspectos que envolvem a produçấo, materializaçáo e vivência do espaço arquitetônico. Ferramentas de projeto assistido pelo computador (Computer Aided Design - CAD) e de modelagem de informação da construção (Building Information Modeling - BIM) tornaram os processos de desenho, compartilhamento e manipulação de informaçáo mais rápidos e precisos. Novos processos de fabricação assistida por computador (Computer Aided Manufacturing - CAM) permitiram aos arquitetos um maior controle sobre a produção e a criação de um novo repertório formal com geometrias complexas (blobs, parametric paneling, waffles entre outros). Estas mudanças incentivaram a criaçấo de um fluxo de novas teorias e de estratégias de projeto baseadas na computação, cada uma com sua promessa de mudança da prática da arquitetura. Algumas destas resultaram em arquiteturas intelectualmente sedutoras, visualmente provocativas e formalmente complexas, porém poucas apontam para uma verdadeira mudança de paradigma no processo de produção do espaço arquitetônico, pois geralmente perpetuam - ou mesmo acentuam - o sistema tradicional de controle do arquiteto sobre o projeto e construção do espaço.
Tradicionalmente, boa parte da produção do arquiteto é baseada na elaboração de desenhos prescritivos que tem como finalidade garantir a produção de objetos que correspondem fielmente ao que foi representado. Para viabilizar a por muitos desejada equivalência entre objeto representado e objeto produzido vários arquitetos utilizam ferramentas cada vez mais avançadas de representaçáo, como modelos eletrônicos, processos BIM, processos paramétricos entre outros. O objetivo comum é possibilitar um crescente controle sobre os processos de produção e evitar erros e imprevistos que inevitavelmente acontecem na construção tradicional. Geralmente o projeto sofre várias alterações, da concepção inicial ao objeto acabado, pois o processo é contingente, ou seja, é influenciado por fatores objetivos e subjetivos externos a ele próprio. Se por um lado um bom projeto é aquele que acomoda as contingências, como proposto por Jeremy Till (2009), por outro, o bom projeto seria aquele que descreve todos os elementos aplicados na construção de maneira detalhada, por meio de um conjunto de instruçôes - algoritmos - na forma de desenhos bidimensionais e tridimensionais, que atuam de forma a restringir as possibilidades de mudança. Atualmente, com a popularizaçấo de novas técnicas de fabricação digital, como as impressoras tridimensionais e máquinas de corte controladas por computador, o objetivo de controle total do processo e do produto idealizado por muitos arquitetos pode estar próximo de ser atingido, ainda que ignorando as contingências.

Esse controle do processo de projeto acontece por restrição. Se antes tal controle por restriçáo era praticamente improvável de se realizar plenamente, atualmente a associação entre processos de 
projeto paramétrico com a fabricaçáo digital tornaram-no possível. A ligação direta entre projeto e fabricação, que Kolarevic (2003) chama de contínuo digital, já é um processo comum na indústria automotiva, aeroespacial e na construção de navios. Porém, foi somente na última década que os avanços nas tecnologias CAD e CAM tem causado mais impacto na produção arquitetônica. Por ser um processo relativamente recente no campo da arquitetura ainda existem muitas dúvidas e desconfianças sobre seus possíveis problemas e benefícios. Seria desejável que o arquiteto retome a posição de controle central dentro da tradição Renascentista, transformando-se no que Kolarevic (2013) chama de digital masterbuilder? É possível pensar novas formas de apropriação dos processos de projeto paramétrico associados a fabricação digital de maneiras não restritivas?

O presente artigo aborda estas duas perguntas por meio da discussão de um experimento e de duas interfaces de design Mattermachinee Sketchchair - que tem como proposta permitir o projeto de objetos que podem ser customizados, manipulados, compartilhados e finalmente produzidos por técnicas de fabricação digital. No campo do design de produtos a possibilidade do usuário de manipular parâmetros tem sido exploradas de modo mais sistemático na última década (Open Design Foundation, Open Design Now). Desta maneira a análise destas interfaces pode contribuir para o debate sobre a abertura de parâmetros ao usuário, que ainda é pouco difundido na arquitetura. Como consequência do deslocamento do foco sobre o objeto para o processo, do projeto para o metaprojeto, estas interfaces apontam para uma possível alternativa ao crescente controle exercido por arquitetos do processo de desenho e construção. Na presente discussão o metaprojeto, pode ser entendido como projeto do projeto, ou como o processo de projeto do processo de projeto, como definido por Andries van Onck em 1963, ou como designing designing segundo John Chris Jones (1991). Em uma alusão a cibernética de segunda ordem cibernética da cibernética - o metaprojeto pode ser comprendido como um projeto de segunda ordem onde o observador faz parte do sistema.

\section{Desenho paramétrico}

Nos processos tradicionais de desenho digital - que utilizam programas CAD como mera extensão digital da prancheta de desenho - a alteração de parâmetros, como a geometria de um cômodo, só pode ser implementada pela supressão e reconstruçáo do desenho. Isso é repensado no processo paramétrico de desenho digital, onde o modelo é definido como um conjunto de relaçóes geométricas que são aplicadas por meio de expressóes gráficas paramétricas e relaçôes condicionantes (Menges,2006). Esta cadeia de relaçóes geométricas pode ser manipulada sem que se perca a consistência do conjunto. Neste processo os objetos não são mais desenhados, mas sim programados a partir das relaçôes dentre diversos parâmetros. Esta nova forma de pensar o processo de projeto abre perspectivas interessantes, pois permite que os parâmetros sejam alterados em qualquer etapa do processo, sem a necessidade de se refazer todos os passos já realizados. Uma interface que ilustra este processo é o já muito difundido Grasshopper (Disponível em: www.grasshopper3d.com), uma interface de programação visual que funciona a partir de um node based editor, onde componentes podem ser conectado a outros através de linhas. Estas conectam um output de determinado componente ao input de outro formando correlaçóes entre os componentes. A título de exemplo, para se desenhar um círculo é necessário estabelecer dois parâmetros, seu centro e raio. O centro é dado por um componente de ponto cartesiano e o raio pode ser estabelecido por uma variável numérica. Talvez o nome original da interface, Explicit History, seria mais apropriado para ilustrar esta cadeia de parâmetros que se correlacionam, já que todos os componentes e variáveis inseridos ao longo do processo são visíveis e podem ser alteradas.

Se os parâmetros podem ser alterados de forma dinâmica isso abre a possibilidade de inserir o usuário final no processo de desenho por meio de interfaces digitais que permitam a interação e manipulação destes parâmetros. Esta abertura de parâmetros de projeto à interação com o usuário pode aumentar de maneira significativa o número de estados possíveis de um determinado sistema, potencializando soluçóes ou situaçóes não previstas. Infelizmente isso parece não acontece na prática, e os arquitetos, ao contrário, enfrentam um problema ético ao restringir o aumento do número de possibilidades a sua prática no escritório, não estendendo elas ao usuário final (Cabral Filho, 2012). Geralmente a abertura possibilitada pelo uso de novas estratégias de design digital, que usam processos paramétricos, não é estendida ao usuário. Porém, existem algumas práticas associadas ao design de objetos, que se baseiam no potencial da abertura de parâmetros de maneira não restritiva, que podem indicar novas formas de criação arquitetônica.

Para investigar o potencial e limitaçóes da abertura de parâmetros de desenho ao usuário foi desenvolvido um metaprojeto de uma luminária chamado de LUPA. Este experimento será comparado a duas outras interfaces existentes - Sketchchair e Mattermachine que têm como proposta permitir o projeto de objetos que podem ser customizados, manipulados, compartilhados e finalmente produzidos por técnicas de fabricação digital.

\section{LU/PA, Sketchchair e Mattermachine}

A luminária LU/PA - acrónimo de luminária paramétrica - é um experimento elaborado para investigar o potencial e limitaçóes da abertura dos parâmetros de desenho ao usuário. A opção pelo desenvolvimento de uma luminária se deu por três razóes: dimensôes apropriadas para fácil fabricação na CNC (Computer Numeric Control) laser disponível no laboratório LAGEAR; baixo custo de fabricação (além do acrílico pode ser feita em papel ou madeira); baixa complexidade técnica.

O metaprojeto da luminária foi desenvolvido no plugin Grasshopper $3 D$ e consiste em quatro cessóes circulares horizontais conectadas por planos verticais posicionados a partir de um eixo central. O usuário pode mudar o diâmetro de cada cessão circular, a distância entre cada uma delas e o número de seçôes verticais. A altura da lâmpada que é posicionada no centro também pode ser alterada. Existe também a opção de fazer o objeto sem a lâmpada para que seja usada outra fonte luminosa ou mesmo para que o objeto tenha outro propósito. 


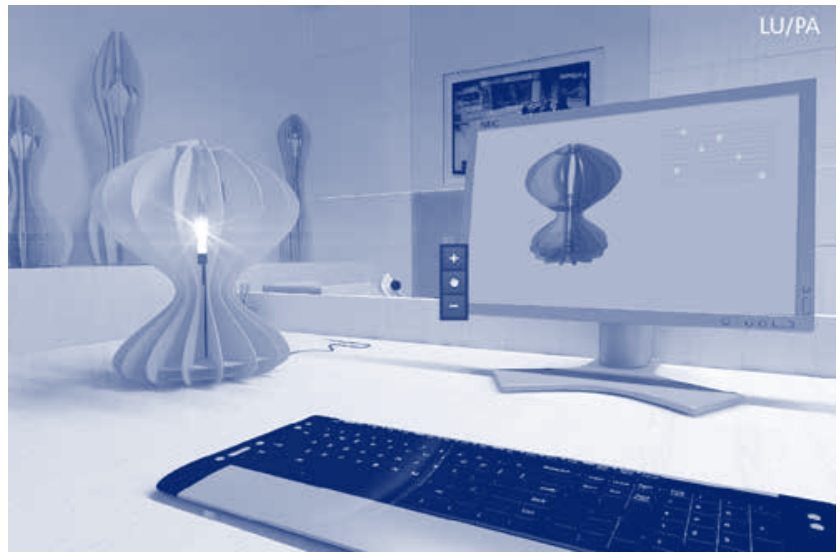

Figura 1: Ilustração da luminária MUSA

Após a escolha de todos os parâmetros o projeto final é automaticamente gerado com os arquivos de corte prontos para serem exportados para a máquina de corte.

Sketchchairé um programa de código aberto desenvolvido para facilitar o desenho de cadeiras direcionadas à fabricação digital. $\mathrm{O}$ sistema permite ao usuário controlar de maneira simples todo o processo de criação de uma cadeira, que inclui o desenho inicial, aperfeiçoamento, testes e fabricação. A interface consiste basicamente em um plano de trabalho 2D com ferramentas de criação e ediçáo de linhas. Todo o processo é baseado no método de fabricação por nervuras, onde o objeto é seccionado nos sentidos longitudinal e transversal formando laminas que se intertravam. O usuário desenha o perfil da cadeira e depois ajustas as camadas e fatias para determinar a forma final. O software também inclui um sistema que permite testar a ergonomia e simular a força gravitacional. $\mathrm{O}$ teste de ergonomia é feito com uma figura que representa o corpo humano e pode adotar diferentes medidas. Para testar a proporção do objeto são disponibilizados diversas imagens de referência. $\mathrm{O}$ produto é um arquivo vetorial com todas as peças da cadeira que pode ser enviado para uma máquina de corte computadorizada ou mesmo impresso e cortado a mão.

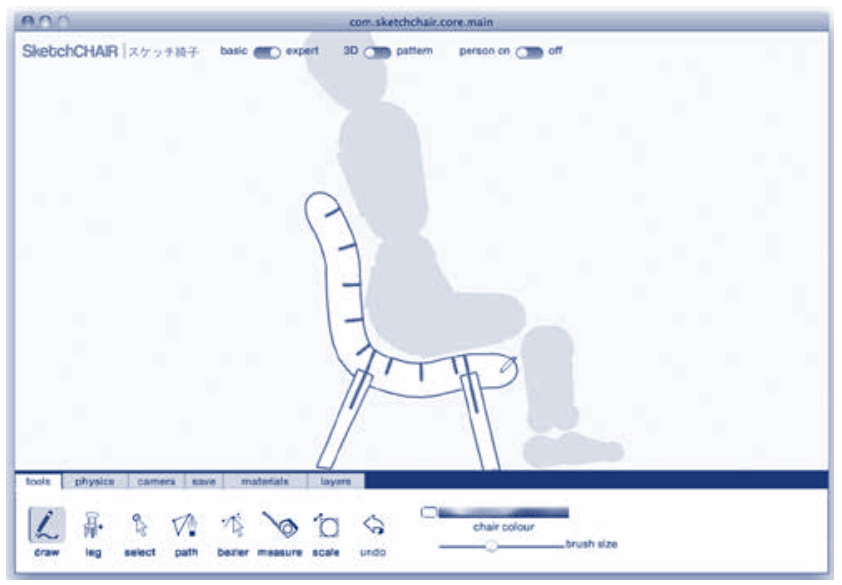

Figura 2: Interface Sketchchair.

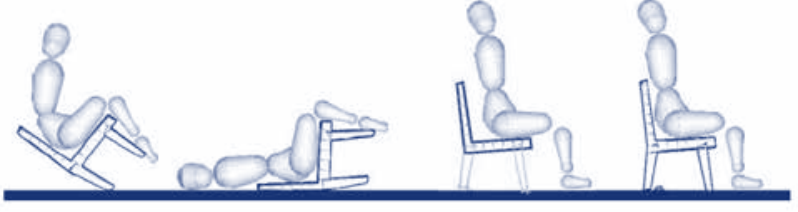

Figura 3: Simulação de teste gravitacional Sketchchair.

O software foi testado em um workshop com sete participantes, de 12 a 53 anos, que foram convidados a desenhar e construir uma maquete da cadeira. Embora este teste não possa ser considerado cientificamente por causa da falta de informaçáo sobre os procedimentos adotados e pelo baixo número de participantes, ele levanta algumas questôes interessantes. De acordo com Saul et al (2012) todos os participantes conseguiram construir uma miniatura da cadeira e acharam a experiência prazerosa. Dos sete participantes seis expressaram preferência pelo seu próprio design no lugar dos vendidos em lojas. Os participantes também indicaram que considerariam a cadeira menos descartável. Embora a possibilidade de desenhar a cadeira a partir do início tenha agradado aos participantes, três deles declararam que gostariam da opção de iniciar a partir de um desenho inicial criado por um designer.

Mattermachine é uma plataforma de desenho paramétrico que permite criar e customizar produtos pela internet. A interface de design, similar ao Grasshopper, é um node based editor onde um componente pode ser conectado a outros através de linhas. Quem desenha o objeto pode permitir que determinadas variáveis sejam alteradas pelos usuários, que podem criar seus próprios desenhos ou acessar os desenhos já elaborados e customizá-los de acordo com suas necessidades. Desta maneira o desenho pode ser construído de forma dinâmica, onde o usuário define a forma final. Neste processo o grau de abertura do objeto à intervenção do usuário é estipulado por quem estabelece os parâmetros iniciais. Mattermachine guarda um banco de dados com todos os objetos desenhados. O usuário pode acessar um destes objetos, alterar seus parâmetros e disponibilizar o produto, gerando um processo colaborativo. Quem desenha o objeto pode optar por distribuir o desenho gratuitamente ou cobrar uma taxa de quem baixar o layout de corte ou códigos para impressão 3D. O programa também permite que diferentes pessoas trabalhem simultaneamente na criação de um mesmo modelo, permitindo uma maior colaboração entre designers, engenheiros, fabricantes, entre outros.

LU/PA, Mattermachine e Sketchchair podem ser associadas ao conceito de design aberto, do inglês open design, definido por Paul Atkinson (2011) como a criação colaborativa de artefatos por um grupo disperso e independente - e de produção individual - e sua fabricaçáo digital direta no local de uso. O conceito esta inserido em um movimento onde indivíduos colaboram para a produçâo cultural, de conhecimento, objetos ou outro tipo de informação, que teve grande impulso a partir do desenvolvimento da internet. Atkinson (2011) observa que dois aspectos devem ser considerados para tornar as tecnologias de desenho aberto mais aceitável para um público maior: o desenvolvimento de interfaces gráficas de usuário mais amigáveis, ou sistemas mais intuitivos para a criaçáo de modelos 


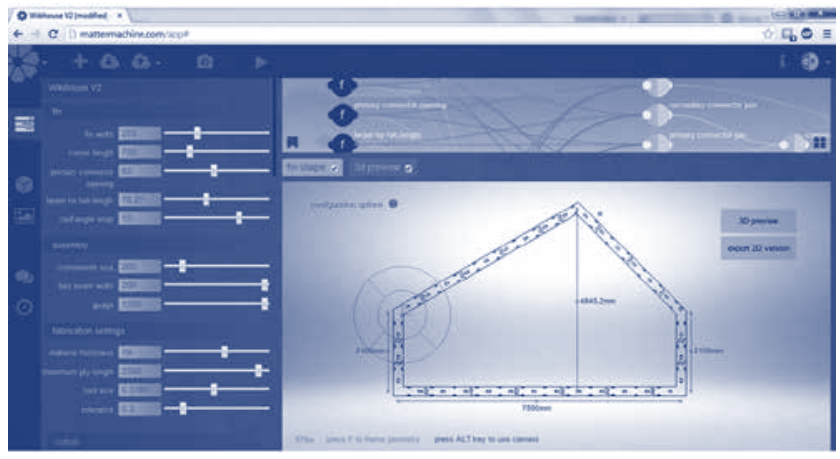

Figura 4: Interface Mattermachine.

tridimensionais; e a distribuição de materiais apropriados para o uso em máquinas de fabricação digital. Mattermachine, Sketchchair e LU/PA abordam o primeiro aspecto de maneiras diferentes. Em LU/PA a interface não se mostra muito amigável já que a cadeia de componentes do plugin Grasshopper $3 D$ pode ter para muitos um aspecto confuso. $\mathrm{O}$ desenho e restrito a combinação de parâmetros deixados abertos e o processo de fabricação é bastante restritivo. Em Mattermachine o desenho e o processo são abertos, permitindo a criação de qualquer objeto por meio de diversos processos de fabricação, mas exigindo um maior conhecimento técnico do usuário. Em Sketchchair, o desenho é aberto, mas o processo é mais fechado e especializado, o que permite um maior suporte técnico para que usuários leigos consigam criar um produto com maior estabilidade e qualidade. Em Sketchchair o papel do designer passa do desenho de objetos fechados para o desenho de interfaces, ou processos, para dar suporte ao usuário criar seu próprio desenho. Jos de Mul (2011) denomina este novo processo de databese design, ou desenho de banco de dados, onde o designer náo desenha os objetos, mas cria um espaço de desenho onde usuários inexperientes podem acessar interfaces amigáveis dentro das quais podem desenhar seus próprios objetos. Neste sentido o designer cria um metaprojeto do objeto que só se materializa como projeto e produto pela interaçáo com o usuário. A criação destes metaprojetos pode representar uma possível alternativa ao crescente controle exercido por arquitetos de todo o processo de desenho e construção, possibilitado pela associação entre as tecnologias digitais de desenho e de fabricação digital.

\section{Controle por restrição e Metaprojeto}

De acordo com a Lei de Requisite Variety de William Ross Ashby (1957), para um determinado sistema controlar o outro é necessário que o sistema controlador tenha no mínimo a mesma quantidade de estados que o sistema controlado. Em sistemas extremamente complexos como a arquitetura o número de estados do sistema é exponencialmente maior do que o número de estados que o arquiteto é capaz de antecipar. Desta maneira a única forma do arquiteto exercer controle sobre o projeto acaba sendo por restrição, diminuindo a variedade do sistema. Glanville (2002) compara este tipo de controle por restrição a sistemas ditatoriais que são estruturados em relaçóes de poder. Neste contexto o arquiteto opera como ditador da forma que restringe as possibilidades de desenho, apropriação e uso. Em contraponto, Glanville (2002) defende que a ausência de controle pode ser uma estratégia para expandir o número de opçóes disponíveis permitindo que sejamos mais criativos. Parte-se do pressuposto de que a ausência ou diminuição de controle permite gerar novidade, ou seja, chegar em algum lugar inesperado. Para Baltazar (2009) uma alternativa de romper com o controle, restrição e prescrição do desenho é pensar a arquitetura como processo aberto, estabelecendo continuidade entre projeto e uso. Jones (1991) defende este deslocamento do produto acabado para o processo, já que o objetivo do design não deve ser um produto com função determinada, mas sim a própria continuidade do processo de design. Para Jones (1991), no processo todas as pessoas são designers. Neste sentido o foco no processo permite a transformação do usuário em coautor do espaço, potencializando seu papel ativo. Este artigo contribui para a investigação de estratégias para possibilitar que esta transformação seja alcançada por meio do metaprojeto, com a abertura dos parâmetros de projeto para manipulação dos usuários.

Com a estratégia de metaprojetos utilizada nas três interfaces descritas é possível que o usuário crie soluçóes rápidas adaptadas a sua necessidade e contexto próprio. $\mathrm{O}$ arquiteto ou designer contribui para esta criação com seu conhecimento técnico e criatividade na construção das interfaces e desenvolvimento dos processos de fabricação. Neste sistema, como os experimentos e resultados são compartilhados é possível criar processos iterativos de constante melhoria dos produtos. O sistema de construção da Wikihouse (disponivel em www.wikihouse.cc) é um exemplo importante de como o metaprojeto pode ser aplicado na arquitetura. Apesar de ser um sistema ainda em desenvolvimento ele agrega colaboradores de diversos países que se agrupam em áreas de pesquisa diferentes, desenvolvendo métodos construtivos, aprimorando os processos e programas, entre outros. A plataforma de código aberto Linux é outra evidência deste processo de melhoria constante pela iteração - um processo circular de construção, crítica e reconstrução - já que é hoje o sistema operacional mais utilizado em dispositivos digitais, o que ratifica sua confiabilidade, qualidade e capacidade de adaptaçáo. Neste processo o usuário pode criar uma relaçáo diferente com o produto, pois é seu co-criador. Isso diminui a chance do produto ser rapidamente descartável e facilita sua manutenção. Este é um dado relevante, se considerarmos que atualmente " $90 \%$ dos recursos tirados do chão se transformam em lixo dentro de três meses" (Thackara, 2011).

Como discutido, no metadesenho a abertura de parâmetros de projeto à interaçáo com o usuário pode aumentar de maneira significativa o número de estados do sistema, gerando soluçóes ou situaçóes não previstas, além dos outros benefícios supracitados. Isso não quer dizer que o desenho aberto ou a produção colaborativa devem ser pensados como única alternativa possível, já que diferentes processos devem coexistir na produção do espaço. O problema hoje é que a indústria, em especial as grandes corporaçôes, atuam para homogeneizar um mercado essencialmente heterogêneo, criando tendências e modismos por meios e métodos já muito debatidos. Neste sentido, o metaprojeto pode ser pensado como estratégia de resistência e de transformaçáo, contra a ditadura da forma, contra o controle e a homogeneização. 


\section{Agradecimentos}

Os autores gostariam de agradecer as agências de fomento FINEP, CAPES, CNPq, Fapemig e Pró-Reitoria de Graduação da UFMG e NPGAU, por suas bolsas e financiamentos às pesquisas.

\section{Referencias}

Atkinson, P. (2011). Orchestral Manoeuvres in Design. In B. v. Abel, R. Klaassen, L. Evers, \& P. Troxler (Eds.), Open design now. Amsterdam: BIS publishers.

Baltazar, A. P. (2009). Cyberarchitecture: the virtualisation of architecture beyond representation towards interactivity ( $\mathrm{PhD}$ thesis), University College London, Unpublished PhD thesis.

Cabral Filho, J. d. S. (2013). The ethical implications of automated computation in design. Kybernetes : an international journal of cybernetics and general systems, 42(9/10), 1354 - 1360. doi:http://dx.doi.org/10.1108/K-10-2012-0067

Glanville, R. (2002). On being out of control.

Jones, J. C. (1991). Part 2 Opus one, number two Designing designing, London: Architecture design and technology press (pp. 158-166).

Menges, A. (2005). Pluripotent Components: An Alternative Approach to Parametric Design AA Files, 63-74.

Mul, J. (2011). Redesigning Design. Open Design Now. Amsterdam: BIS publishers.

Poerksen, B. (2911). Ethics of Enabling Ethics. Cybernetics \& Human Knowing, 18, 143-149.

Thackara, J. (2011). Into the Open. Open Design Now. Amsterdam: BIS publishers.

Till, J. (2009). Architecture depends. Cambridge: MIT Press. Van Onck, A. (1965). Metadesign. Bibliografia FAUUSP. 